\title{
The athlete's heart: is big beautiful?
}

\author{
Roy J Shephard
}

\begin{abstract}
Development of the concept of "athlete's heart" is traced through early clinical and radiographic studies to modern echocardiography and magnetic resonance imaging. It is noted that the lower limits of criteria for the diagnosis of a "pathological" enlargement of the heart have frequently been revised in an upward direction, as the prevalence of large hearts has been recognised in both endurance and power sports competitors who are in good health. Belief that hypertrophic cardiomyopathy is the commonest cause of sports related death in young adults is traced to weak diagnostic criteria and frequent republication of a very small group of cases. Although the existence of a congenital myocardial dystrophy is now well established, this condition is extremely rare, and has no particular predilection for athletes. Genetically based screening tests may become available in the future, but the exclusion of young adults from sports participation on echocardiographic criteria appears costly and ineffective. For most people, the development of a large heart is not a pathological sign - rather, it is a desirable outcome that will enhance performance on the sports field, and will allow longer independence in old age.

(Br F Sports Med 1996;30:5-10)
\end{abstract}

Key terms: athletic screening; cardiac hypertrophy; echocardiography; sudden death

Osler ${ }^{1}$ commented "no man becomes a great runner or oarsman who has not naturally a capable if not a large heart". Nevertheless, for many years a substantial proportion of sports physicians were worried that the large heart of the endurance athlete, far from being advantageous, was actually a risk factor for sudden death on the sports field "because it indicates undue strain or because of the danger of eventual degeneration". ${ }^{2}$

In the early days of the Olympian movement, Henschen $^{3}$ was able to demonstrate enlargement of the heart in cross country skiers by careful percussion of the chest. He wrote "an enlarged heart is a good thing if it can perform more work over an extended period of time". Other features that can be detected on simple clinical examination include a prominent, displaced apical impulse and a right ventricular lift. ${ }^{4}$ However, recognition of the large heart of endurance competitors became more widespread with the advent of radiography, as examination of the cardiac shadow began to supplement the very crude percussion techniques of clinicians such as Henschen.

At first, PA radiographs were used simply to measure cardiothoracic ratios. ${ }^{2}$ Investigators quickly found that the cardiothoracic ratios of many athletes approached or exceeded the anticipated normal limit of $0 \cdot 50 .^{5-7}$ Soon, German cardiologists with an interest in sports medicine had added a lateral view to the PA radiograph, ${ }^{8}$ and by taking three linear measurements from the radiographs, an estimate of cardiac volume was obtained. The measurement necessarily remained imprecise, for unless the $x$ ray machine was ECG triggered, the radiographs might have been obtained either in systole or in diastole! In an average young man, the reported volume was about $700 \mathrm{ml}$, but in an endurance athlete the figure could rise as high as $1000-1100 \mathrm{ml}$, apparently without adverse consequences for health.

Later, the radiographic information was combined with an examination of ECG voltages. ${ }^{9}$ Left ventricular hypertrophy was diagnosed if the sum of SV1 and RV5 exceeded 35 $\mathrm{mm}(3.5 \mathrm{mV})$, and right ventricular hypertrophy if the sum of RV1 and SV5 exceeded $10.5 \mathrm{~mm}(1.05 \mathrm{mV}) .^{1011}$ Using such criteria, it was estimated that $14-85 \%$ of Olympic athletes and marathon runners had developed left ventricular hypertrophy. ${ }^{12}$ Other investigators developed more complicated evaluations of the ECG, based on voltage and nonvoltage criteria, ${ }^{13}{ }^{14}$ but correlations with radiographic, echocardiographic, or ultimate necropsy evaluations remained poor, ${ }^{15}$ in part because the hypertrophy of the chest muscles typical of many athletes attenuated electrocardiographic voltages. ${ }^{4}$

At this period in medical history, many of the population suffered from cardiac enlargement due to after effects of rheumatic heart disease such as mitral regurgitation. In such individuals, the size of the heart increased with the severity of the disease process, and it is thus not surprising that many physicians, particularly in North America, also regarded the cardiac enlargement of an endurance athlete as an adverse sign. It is not easy to distinguish physiological from pathological hypertrophy on PA chest radiographs. In principle, there are important differences of appearance between the rheumatic heart and the heart of the endurance athlete. In a person with the end 
results of rheumatic valvar disease, the enlarged cardiac shadow is due mainly to a poor ejection fraction, so that the end systolic volume of the left ventricular chamber is generally increased. In contrast, much of the increase in end systolic cardiac dimensions of the endurance athlete is due to a hypertrophy of the ventricular wall. The firm, rounded contours of the hypertrophied heart should thus stand in marked contrast with the sagging distended form of a failing myocardium. ${ }^{16}$ However, in practice the PA cardiac silhouette is formed by variable contributions from the two ventricles and the atria, and it proved very difficult to distinguish the left ventricle from the other chambers. Many physicians were also slow to admit that they had erred in fulminating against competitors with a supposed pathological enlargement of the heart. Thus warnings against "athlete's heart" continued until quite recently. ${ }^{17-20}$

\section{Echocardiographic and magnetic resonance imaging data}

As is commonly the case in medical science, technological developments - the introduction of wide angle, two dimensional echocardiography $^{21-23}$ and magnetic resonance imaging ${ }^{24} 25$ led to new interest in the "athlete's heart" and hypertrophic cardiomyopathy as possible causes of sudden, exercise related death in athletes. Rost and Hollmann ${ }^{26}$ went so far as to describe hypertrophic myocardiopathy as an "ultrasound-specific" disease.

The new techniques allowed cardiologists to make relatively accurate measurements of both wall thicknesses and the dimensions of the ventricular chambers. ${ }^{27} \mathrm{~A}$ much clearer distinction could now be drawn between the distended heart of the person with cardiac failure and the strong hypertrophied heart of the person who was in good physical condition. Echocardiography also suggested differences between the heart of the endurance athlete, where the thicker ventricular walls seemed an adaptation to an increase in volume loading of the heart, and the heart of the competitor in sports with an isometric demand, where there was a thickening of both septal and free walls of the ventricle without any increase in left ventricular end diastolic diameter. ${ }^{12} 23$ 28-30 Nevertheless, the limits of resolution for echocardiography, approximately $2 \mathrm{~mm}$ for an individual measurement, ${ }^{31}$ remain of a similar order to many of the differences that have been discussed, both between athletes and sedentary individuals, and between the healthy and those with supposedly pathological enlargement of the heart. As with many laboratory procedures, the methodology allows the detection of group differences but provides limited information on the status of the individual patient.

Echocardiographic studies have shown as many as $60 \%$ of endurance athletes with a posterior wall diastolic thickness that exceeded the supposed normal value of $11 \mathrm{~mm} .{ }^{6732}{ }^{33} \mathrm{In}$ consequence, normal limits for diastolic wall thickness have been revised upward, to 16 $\mathrm{mm},{ }^{34-36} 18 \mathrm{~mm},{ }^{37}$ or even $19 \mathrm{~mm} .^{38}$ The new standards have left little margin of distinction between physiological hypertrophy and the $17-18 \mathrm{~mm}$ wall thickness typical of pathological forms of pressure overload (aortic stenosis, hypertension) or volume overload (aortic or mitral regurgitation)..$^{15}$ Moreover, it is hard to believe that the hypertrophy seen in the athlete has any pathological significance, since even very high values regress towards normality over several months of inactivity, and the regression of moderate hypertrophy can be even more rapid. ${ }^{39}$

Part of the apparent problem is dimensional. Many athletes have a body mass that is much above the population average, and, if the cardiac dimensions of endurance athletes are expressed per unit of lean body mass, only the septal thickness is usually greater than in control subjects. ${ }^{40}$ In resistance athletes, the body mass is usually very high, but the heart weight per $\mathrm{kg}$ of body mass remains normal. ${ }^{28-30} 41$

\section{Diagnoses based on septal thickness and ventricular cavity ratios}

In recent years, the diagnosis of pathological enlargement has been based upon the thickness of the interventricular septum and the calculation of various ratios. There is substantial hypertrophy of the interventricular septum in both endurance and resistance athletes, but again it is hard to accept this as a pathological finding, given its wide prevalence. Some $60 \%$ of basketball players ${ }^{7}$ and $83 \%$ of child swimmers ${ }^{42}$ have septal thicknesses that exceed accepted norms for sedentary populations.

Many cardiologists have been concerned if the ratio of interventricular septum to left posterior ventricular wall thickness exceeded some arbitrary limit (commonly 1.3:1). ${ }^{12}$ But in fact septum to wall thickness ratios can rise as high as 2.0 in athletes, much higher than the values that are encountered in patients with pathological pressure or volume overload, ${ }^{7} 4344$ and it has yet to be shown convincingly that the high ratios observed in athletes are either dangerous or pathological. ${ }^{12}$ Oakley and Oakley $^{45}$ instanced an athlete who had a ratio of $1 \cdot 5$. Four years after ceasing training, both the electrocardiogram and the echocardiogram of this individual were interpreted as normal.

Perhaps the most useful diagnostic measurement is the ratio of septal thickness to left ventricular end systolic or end diastolic diameter. ${ }^{29}{ }^{43}{ }^{46-48}$ Currently, the upper limit of normality for the septal thickness to end systolic diameter ratio has been set at 0.48 (3 SD above normal values). ${ }^{12}$ Other potential indicators of pathological enlargement include a discrepancy between cardiac dimensions and ergometric performance ${ }^{29}$ and associated abnormalities of cardiac rhythm.

\section{Cardiac hypertophy and myocardial ischaemia}

Many physicians have found it hard to believe that it is acceptable for the thickness of the heart wall to increase to the extent that is observed in top athletes. Although a little hypertrophy might help competitive performance, if a thickness or a thickness ratio 
increased beyond some figure (which it has been necessary to revise repeatedly in an upward direction), then they have maintained that the condition should be regarded as pathological, particularly if there are associated ECG abnormalities, limited ventricular compliance, or poor diastolic filling. ${ }^{49}$

It has been argued that as the cross section of the ventricular wall is increased, the diffusion pathway from the myocardial capillaries to the cardiac mitochondria is increased, leaving the heart more vulnerable to ischaemia and such fatal complications as cardiac arrest or ventricular fibrillation. Further, it has been recognised that in some instances, the situation of the enlarged heart is aggravated by a congenitally determined myocardial dystrophy, ${ }^{50-54}$ with consequent disturbance of the electrical pathway, ${ }^{55}$ mitral regurgitation, ${ }^{34}$ or hypotension. ${ }^{56}$

There are several fallacies in the argument that an increase in heart size necessarily predisposes the individual to myocardial ischaemia. Firstly, when the heart hypertrophies, there is generally a parallel development of the myocardial capillaries, as in hypertrophied skeletal muscle. Thus the blood supply to a hypertrophied heart remains at least as good as that to a hypotrophic heart. More importantly, the main determinants of myocardial hypoxia are (1) the relation of myocardial work rate to myocardial oxygen supply, (2) the tension developed in the ventricular wall, and (3) the relative duration of the systolic phase of the cardiac cycle.

(1) Relation of myocardial work rate to myocardial oxygen supply - The myocardial work rate during a bout of exercise is approximated by the product of heart rate and systolic blood pressure. Because of myocardial hypertrophy, the endurance athlete has a large ejection fraction, and can sustain a larger stroke volume than a less well trained person during vigorous exercise. From this, it follows that a given external task can be performed at a lower heart rate and a lower cardiac work rate than would be the case in a sedentary individual (although of course the athlete will usually exercise to a much higher peak work rate than an untrained person). The myocardial oxygen consumption at a given external work rate is correspondingly reduced in the athlete, so that during ordinary daily life the risk of myocardial ischaemia is much less than in a sedentary person.

(2) Tension developed in the ventricular wall According to the Law of LaPlace (as modified for a thick walled structure), the total tension exerted by the ventricular wall is approximately proportional to the product of intraventricular pressure and the average ventricular radius. ${ }^{57}$ In the endurance athlete, the large average radius of the ventricle may cause some increase of tension for a given arterial pressure. But because the cross section of the ventricular wall is also much greater in the athlete than in a sedentary individual, the force exerted per unit of wall cross section at any given level of intraventricular pressure is actually lower in the athlete than in the untrained person. ${ }^{55}$

(3) Relative duration of the systolic phase of the cardiac cycle - The tension in the ventricular wall is high during systole, irrespective of the individual's training status. The high intramural pressure occludes perforating coronary vessels, and myocardial perfusion thus occurs mainly during diastole. Because ventricular hypertrophy is associated with a large stroke volume, the heart rate is slower and the relative length of the diastolic phase of the cardiac cycle is much longer for an athlete than for a sedentary person, both at rest and at a given submaximal work rate. This in turn allows greater myocardial perfusion in an athlete than in a sedentary person for much of the day, although training has little influence upon the heart rate during maximal effort.

\section{Risk of sudden death during exercise}

One of the main reasons for fear of hypertrophic cardiomyopathy is that occasionally a young endurance athlete dies on the sports field. ${ }^{5158}$ It is reasoned that cardiac hypertrophy provides an explanation of such deaths, and that the condition should have been detected by a careful preparticipation examination, ${ }^{59-62}$ despite growing evidence that attempts at preparticipation screening are not cost-effective. ${ }^{63}$

The causes of sudden, exercise related death in the young athlete are varied..$^{54-67}$ Sometimes there is an undetected congenital anomaly - for instance, an abnormal origin of the coronary vessels - so that the chances of myocardial ischaemia during intensive exercise are increased. Sometimes there is an aneurysm of the circle of Willis which ruptures, causing death from cerebral bleeding. Sometimes there is an infection of the myocardium due to recent influenza or some other viral disorder. But where no other cause can be assigned, blame is attached to myocardial hypertrophy, particularly a hypertrophy of the interventricular septum. Details of the hypothesis have changed a little in recent years - in place of fears regarding myocardial ischaemia, many cardiologists now argue that myocardial hypertrophy affects the electrical conducting system, and that this predisposes to abnormalities of heart rhythm. Others maintain that the underlying problem is almost always an inherited dystrophy of cardiac muscle with a disarray of the myocardial fibres, and that there is little relation between ventricular hypertrophy and sudden death in the absence of this anomaly. ${ }^{56}$

Many investigators have attached blame to an excessive interventricular septal thickness, a finding commonly established only at necropsy examination. However, the dice seem heavily loaded in favour of proving that septal hypertrophy is associated with athletic deaths, since training thickens both the ventricular wall and the interventricular septum, and the necropsy examination is being performed upon a person who has died on the sports field.

In order to establish the postulated pathological significance of septal thickening, it would be necessary to make either a prospective comparison of outcomes between athletes with supposedly normal septa and those with thickened septa, or alternatively to carry out a blinded necropsy comparison between 
athletes who died on the sports field and others at a similar level of training who were killed in traffic accidents. The practical problem in arranging a prospective trial of this type is that the sudden death of young athletes on the sports field is an extremely rare event. Most physicians who are interested in studying the question have difficulty in accumulating more than 10 or 20 personal cases over a lifetime of practice, and in only a small proportion of the 10 or 20 cases is myocardial hypertrophy even a potential explanation of the incident. The costs of organising a prospective trial that would have a reasonable statistical probability of demonstrating a difference of septal thickness between athletes who die and those who survive would thus seem prohibitively large. Possibly, such a trial could be arranged on a cooperative, multicentre basis, by having each of a group of investigators identify and follow athletes where the septum appeared to be extremely thick, following also two or three control subjects with normal septa, but matched for their involvement in endurance sport.

An alternative approach would be to focus retrospectively upon those who have died during athletic competition. The distribution of septal thicknesses in this population could then be compared with that of a second group of endurance athletes who were killed in traffic accidents. In order to obtain adequate numbers, the trial would have to be organised on a multicentre basis, and one immediate obstacle would be that whereas details of the athletic involvement of a person dying on the sports field would be readily available at the inquest, it would be difficult to obtain adequate detail on the sports histories of those involved in traffic accidents, or indeed to ensure that other aspects of personal lifestyle were well matched between the two groups of cases.

We may conclude that (1) the case against cardiac enlargement is currently far from established, and (2) experimental obstacles are such that it will be difficult to obtain conclusive proof from either prospective trials or retrospective necropsy examinations in the foreseeable future.

\section{Sudden death from hypertrophic cardiomyopathy}

Some investigators have boldly claimed that hypertrophic cardiomyopathy is the commonest cause of death in young athletes. ${ }^{17-19} 37{ }^{68} \mathrm{In}$ fact, extreme forms of "athlete's heart" are quite uncommon, even in highly conditioned athletes, and the total number of exercise related deaths is very low (for example, around 100 per year in the USA). ${ }^{67}$ Most incidents occur in the coronary-prone age range, and are probably due to coronary atherosclerosis rather than ventricular hypertrophy. A computerised search of the literature ${ }^{64}$ covering a 50 year period unearthed a total of four likely cases of hypertrophic cardiomyopathy in athletes who were under the age of 40 years!

The conclusion that hypertrophic cardiomyopathy is a common cause of exercise related death seems to have stemmed from a paper by Maron et al. ${ }^{18}$ These investigators collected case histories on 29 athletes between the ages of 13 and 30 who had died in the USA over a period of several years; 19 of the 29 were said to have hypertrophic cardiomyopathy, although only in eight of the 19 did the septum to free wall ratio meet the minimum diagnostic criterion of $1 \cdot 3 / 1 \cdot 0$. At best, the whole hypothesis seems to have been built upon less than two deaths per year across the United States! Others have used extremely loose criteria, classifying as "probable hypertrophic cardiomyopathy" all deaths where the cardiac mass exceeded $400 \mathrm{~g}$ in the absence of other systemic, valvar, or cardiac disorders. ${ }^{37}$ Even when this simplistic approach was adopted, the total incidence across the USA was apparently only about five cases per year. Spirito et al ${ }^{68}$ have further pointed out that almost all reports of the condition around the world have come from two laboratories. The view that the condition is widely prevalent is due, at least in part, to a repeated description of the supposed 19 cases of Maron et al ${ }^{18}$ in a minimum of 25 independent publications.

There remains the possibility that the individual who dies while exercising is affected by an extremely rare inherited malformation of the $\beta$ myosin heavy chain, ${ }^{69}$ but there is no particular reason for this disorder to affect endurance athletes. Moreover, the overall frequency of the anomaly is hardly high enough to form a basis for health policy.

\section{Epidemiological evidence}

In deciding upon the health significance of cardiac hypertrophy, we are left with a final epidemiological option. We know that on average, endurance athletes have a larger heart than sedentary individuals or competitors in other types of sport. What is the longevity of the endurance athlete relative to that of the general population?

A recent study by Sarna and associates ${ }^{70}$ looked at a sample of 2613 athletes who had represented Finland in either the Olympic Games, the World championships, or the European championships between 1920 and 1965 . Endurance athletes survived to an average age of 75.6 years, compared with 69.9 years in a sample of 1712 sedentary adults, and 71.5 years for those who had been Finish champions in power sports. Thus there was no evidence that participation in endurance activity had led to any shortening of lifespan - rather, survival appeared to be enhanced by such competition. Sarna et al adjusted their data for a number of covariates, but the comparison remains incomplete, since there are likely to have been differences of personal lifestyle, particularly cigarette consumption, between the endurance athletes and the general population. The effect of cigarette smoking is sufficiently powerful to have masked any small disadvantage from exercise precipitated sudden death. Moreover, it is uncertain how far either endurance athletes or the participants in power sports continued their exercise involvement in the long interval between competition and the average age at death. 
Given that any risk of death during exercise is extremely small, and we cannot design a satisfactory experiment to see whether cardiac enlargement contributes to this phenomenon, the best advice for the moment is probably to avoid costly and ineffective preparticipation medical examinations that could precipitate costly invasive procedures, cardiac phobias, and premature cessation of sports involvement in those successful athletes who have large hearts. ${ }^{63}$

\section{Benefits of cardiac hypertrophy}

To this point, we have not considered possible benefits of cardiac hypertrophy. It is well established that cardiac hypertrophy is associated with a large stroke volume and thus a large maximum cardiac output. Peak oxygen transport in turn is closely associated with peak cardiac output. Thus the person with a large heart is likely to have a large maximum oxygen intake. In consequence, they are able to undertake any given physical task at a correspondingly smaller fraction of their maximum oxygen intake. Many aspects of exercise related strain, from the increase of blood pressure to the sense of personal fatigue, are less for the person who has developed a large maximum oxygen intake.

If cardiac hypertrophy is advantageous for a young person, it becomes even more important for an older individual. Peak oxygen intake decreases progressively with each year of survival beyond early adult life. In a sedentary person, the loss averages about $500 \mu \mathrm{l} \cdot \mathrm{kg}^{-1} \cdot \mathrm{min}^{-1}$ per year. ${ }^{71}$ Thus, by the age of $75-80$ years, a sedentary person lacks a sufficient margin of aerobic power to climb even a slight slope without becoming excessively breathless. Soon, even the minor chores of daily life become very fatiguing, and the last 10 years of life are spent in growing institutional dependency.

The rate of aging in an endurance athlete is difficult to ascertain, because the volume of training is often reduced as a competitor becomes older. But tests on those who have maintained their training programmes suggest that the absolute rate of deterioration may be a little slower than in a sedentary person - a number of estimates for active individuals lie in the range $400-450 \mu \mathrm{l} \cdot \mathrm{kg}^{-1} \cdot \mathrm{min}^{-1}$ per year. ${ }^{72}$ Given a much higher initial aerobic power, and possibly a slightly slower aging effect, the endurance athlete has a much greater maximum oxygen intake than a sedentary person at any given age during their retirement years. Equating subjects in terms of oxygen transport rather than chronological age, the advantage to the endurance competitor may be as much as a 10-20 year reduction of biological age. ${ }^{71}$ Thus such a person does not need institutional support until an age of 90 or even 100 years. Given that regular exercise has a much smaller influence upon the survival prospects of an elderly person, ${ }^{73}{ }^{74}$ the probability is that an endurance athlete will die before physical condition has deteriorated to the point that extensive institutional support is required.

This seems an important argument in favour of developing and maintaining a large heart.
Physicians have for too long worried about the one in 10 million chance that athletic participation might cause sudden death, while neglecting the growing problem of sedentary senior citizens who require full time care in geriatric wards. Survival prospects are probably increased somewhat by endurance exercise. ${ }^{73}$ But survival alone is not the most important goal of treatment. The true assessment of medical advice is its impact upon quality adjusted life expectancy. ${ }^{75}$ And in such terms, a large heart is indeed beautiful.

\section{Conclusions}

Although ventricular hypertrophy is sometimes suggested to be the commonest cause of sudden exercise related death in the young adult, the total number of exercise induced deaths is very small, and their relationship to ventricular hypertrophy is far from established. There is a rare inherited form of myocardial dystrophy that predisposes to sudden death, but this is not peculiar to athletes. Detailed preparticipation studies of an athlete's heart are unwarranted unless there is a family history of early cardiac death. In general, the "athlete's heart" is a beneficial adaptation to training, enhancing work capacity and reducing the likelihood of dependency in old age.

Dr Shephard currently receives funding as the Canadian Tire Acceptance Limited Resident Scholar in Health Studies a Brock University.

1 Osler W. The principles and practice of medicine. New York Appleton, 1892:635.

2 Keys A, Friedell HL. Size and stroke of the heart in young men in relation to physical activity. Science 1938; men in 8 .

3 Henschen S. Skilanglauf und Skiwettlauf. Eine medizinische Sport Studie. Jena: Mitt med Klin Uppsala, 1899. (Cited by Rost and Hollmann, ref 26.)

4 Park RC, Crawford MH. Heart of the athlete. Curr Probl Cardiol 1985;10:1-73.

5 Gott PH, Roselle HA, Crampton RS. The athletic hear syndrome. Arch Intern Med 1968;122:340-4

6 Raskoff WJ, Goldman S, Cohn K. The athletic heart. fAM 1976;236:158-62.

7 Roeske WR, O'Rourke RA, Klein H, Leopold G Karliner JS. Noninvasive evaluation of ventricular hypertrophy in professional athletes. Circulation 1976;53: 286-92.

8 Reindell H, König K, Roskamm H. Functionsdiagnostik des gesunden und kranken Herzens. Stuttgart: Thieme, 1966.

9 Bramwell C, Ellis R. Some observations on the circulatory mechanism in marathon runners. $Q f \mathrm{~J}$ M 1931; 24:329-46.

10 Sokolow M, Lyon TP. The ventricular complex in left ventricular hypertrophy as obtained by unipolar precordial and limb leads. Am Heart $\mathcal{f}$ 1949;37:161-86.

11 Sokolow M, Lyon TP. The ventricular complex in right ventricular hypertrophy as obtained by unipolar precordial and limb leads. Am Heart $\mathcal{F}$ 1949;38:273-94.

12 Huston TP, Puffer JC, Rodney WM. The athletic heart syndrome. N Engl f Med 1985;313:24-32.

13 Romhilt DW, Estes EH. Point score system for the ECG diagnosis of left ventricular hypertrophy. Am Heart 1968;75:752-8.

14 Scott RC. Ventricular hypertrophy. Cardiovasc Clin 1973; 5:219-54.

15 George KP, Wolfe LA, Burggraf GW. The "Athletic Heart Syndrome". A critical review. Sports Med 1991;11: 300-31.

16 Shephard RJ. Endurance fitness, 1st ed. Toronto: University of Toronto Press, 1969.

17 Brandenburg RO. Syncope and sudden death in hypertrophic cardiomyopathy. $\mathcal{f}$ Am Coll Cardiol 1990;15: 962-4.

18 Maron BJ, Roberts WC, McAllister HA, Rosing DR Epstein SE. Sudden death in young athletes. Circulation 1980;62:218-29.

19 Nienhaber CA, Hiller S, Spielmann RP, Geiger $M$, Kuck H. Syncope in hypertrophic cardiomyopathy: multivariate analysis of prognostic determinants. $\mathcal{F} \mathrm{Am}$ Coll Cardiol 1990;15:948-55.

20 Sandric S. Echocardiography in sports medicine: clinica diagnostic possibilities and limitations. In: Lubich $\mathrm{T}$ Venerando A, eds. Sports cardiology. Bologna: Aulo Gaggi, 1980:707-16. 
21 Dickhuth HH, Jakob E, Staiger L, Keul J. Two dimensional echocardiographic measurements of left ventricular volume and stroke volume of endurance athletes and volume and stroke volume of endurance athle

22 Maron BJ, Gottdiener J, Bonow RO, Epstein SE. Hypertrophic cardiomyopathy: cardiomyopathy with unusual trophic cardiomyopathy: cardiomyopathy with unusual by M-mode echocardiography Circulation 1981;63: by $M-m$

23 Morganroth J, Maron BJ, Henry WL, Epstein SE. Comparative left ventricular dimensions in athletes. $A n n$ Intern Med 1975;82:521-4.

24 Fleck SJ, Henke C, Wilson W. Cardiac MRI of elite junior Olympic weightlifters. Int $\mathcal{f}$ Sports Med 1989;10:329-33.

25 Milliken MC, Stray-Gundersen J, Pesjock RM, Katz J, Mitchell JH. Left ventricular mass as determined by magnetic resonance imaging in male endurance athletes. Am f Cardiol 1988;62:301-5.

26 Rost R, Hollmann W. Cardiac problems in endurance sports. In: Shephard RJ, Åstrand PO, eds. Endurance in sport. Oxford: Blackwell Scientific Publications, 1992: sport. Ox-51.

27 Reichek N, Devereux RB. Left ventricular hypertrophy: relationship of anatomic, echocardiographic and electrocardiographic findings. Circulation 1981;63:1391-8.

28 Snoeckx LHEH, Abeling HFM, Lambregts JAC, Schmitz JJF, Verstappen FTJ, Reneman RS. Echocardiographic dimensions in athletes in relation to their training programs. Med Sci Sports Exerc 1982;14:428-34.

29 Urhausen A, Kindermann W. Echocardiographic findings in strength- and endurance-trained athletes. Sports Med 1992;13:270-84.

30 Zeppilli S, Sandric S, Cecchiti F, Spataro A, Fanelli R. Echocardiographic measurements of cardiac arrangements in different sports activities. In: Lubich $T$, Venerando A, eds. Sports cardiology. Bologna: Aulo Gaggi, 1980:723-34.

31 Perreault H, Turcotte RA. Exercise-induced cardiac hyper trophy. Fact or fallacy? Sports Med 1994;17:288-308.

32 Ikåheimo MJ, Palatsi IJ, Takkunen JT. Noninvasive evaluation of the athletic heart: sprinters versus endurance runners. Am 7 Cardiol 1979;44:24-30.

33 Parker BM, Londeree BR, Cupp GV, Dubiel JP. The noninvasive cardiac evaluation of long-distance runners. Chest 1978;73:376-81.

34 Shapiro LM. Left ventricular hypertrophy in athletes in relation to the type of sport. Sports Med 1987;4:239-44.

35 Spirito P, Pelliccia A, Proschan MA, Granata M, Spataro A, Bellone P, et al. Morphology of the "athlete's heart" representing 27 sports. Am $\mathcal{f}$ Cardiol 1994;74:802-6.

36 Williams CC, Bernhardt DT. Syncope in athletes. Sports Med 1995;19:223-34.

37 Van Camp SP, Bloor CM, Mueller FO, Cantu R, Olson HG. Nontraumatic sports death in high school and college athletes. Med Sci Sports Exerc 1995;27:641-7.

38 Reguero JJR, Cubero GI, de la Iglesia JL, Terrados N, Gonzalez V, Cortina R, et al. Prevalence and upper limit of cardiac hypertrophy in professional cyclists. Eur $\mathcal{f} A p p l$ Physiol 1995;70:375-8.

39 Ehsani AA, Hagberg JM, Hickson RC. Rapid changes in left ventricular dimensions and mass in response to physical conditioning and deconditioning. Am f Cardiol 1978; 42:52-6.

40 Hagan RD, Laird WP, Gettman LR. The problems of per-surface areas and per-weight standardization indices in the determination of cardiac hypertrophy in endurance-trained athletes. $\mathcal{F}$ Cardiopulm Rehabil 1985; 5:554-60.

41 Longhurst JC, Kelly AR, Gonyea WJ, Mitchell JH. Echocardiographic left ventricular masses in distance runners and weight lifters. $\mathcal{F} A$ ppl Physiol 1980;48:154-62.

42 Allen HD, Goldberg SJ, Sahn D, Schy N, Wojcik R. A quantitative echocardiographic study of champion quantitative echocardiographic study of cham
childhood swimmers. Circulation 1976;55:142-55.

43 Menapace FJ, Hammer WJ, Ritzer TF, Kessler KM, Warner HF, Spann JF, et al. Left ventricular size in competitive weight lifters: an echocardiographic study. Med Sci Sports Exerc 1982;14:72-5.

44 Shapiro LM. Physiological left ventricular hypertrophy. $\mathrm{Br}$ Heart f 1984;52:130-5.

45 Oakley DG, Oakley CM. Significance of abnormal electrocardiograms in highly trained athletes. Am $\mathcal{F}$ Cardiol 1982;50:985-9.

46 Colan SD, Sanders SP, Borow KM. Physiologic hypertrophy: effects on left ventricular systolic mechanics in athletes. F Am Coll Cardiol 1987;9:776-83.

47 Dickhuth HH, Röcker K, Hipp A, Heitkamp HC, Keul J. Echocardiographische Befunde beim Sportherz. In: Rost $\mathrm{R}$, Webering F, eds. Kardiologie im Sport. Köln: Deutscher Artze Verlag, 1987:132-45.

48 Pearson AC, Schiff M, Mrosek D, Labovitz AJ Williams GA. Left ventricular diastolic function in weight lifters. Am 7 Cardiol 1986;58:1254-9.
49 Hillis WS, McIntyre PD, Maclean J, Goodwin JF McKenna WJ. Sudden death in sport. BMF 1994; 309:657-60.

50 Rosenzweig A, Watkins H, Hwang D-S, Miri M, McKenna W, Traill TA, et al. Preclinical diagnosis of familial hypertrophic cardiomyopathy by genetic analysis of blood lymphocytes. N Engl f Med 1991;325:1753-60.

51 Sadaniantz A, Thompson PD. The problem of sudden death in athletes as illustrated by case studies. Sports Med 1990;9:199-204.

52 Solomon SD, Jarcho JA, McKenna W, GeisterferLowrance A, Germain R, Salerni R, et al. Familial hypertrophic cardiomyopathy is a genetically heterogeneous disease. 7 Clin Invest 1990;86:993-9.

53 Thierfelder L, Watkins H, MacRae C, Lamas R, McKenna W, Vosberg H-P, et al. Alpha tropomyosin and cardiac troponin T mutations cause familial hypertrophic cardiomyopathy: a disease of the sarcomere. Cell cardiomyopathy:

54 Wigle ED, Sasson Z, Henderson MA, Ruddy TD, Fulop $\mathrm{J}$, Rakowski $\mathrm{H}$, et al. Hypertrophic cardio myopathy. The importance of the site and the extent of hypertrophy. A review. Prog Cardiovasc Dis 1985;28:1-83.

55 Maron BJ, Isner JM, McKenna WJ. Hypertrophic cardiomyopathy, myocarditis and other myopericardial diseases and mitral valve prolapse. Med Sci Sports Exerc 1994;26:S261-7.

56 McKenna WJ, Camm AJ. Sudden death in hypertrophic cardiomyopathy. Assessment of patients at high risk. Circulation 1989;80:1489-92.

57 Shephard RJ. Physiology and biochemistry of exercise. New York: Praeger Publishing, 1982.

$58 \mathrm{Kohl}$ HW, Powell KE. What is exertion-related sudden cardiac death? Sports Med 1994;17:209-12.

59 Dickhuth HH, Röcker K, Hipp A, Heitkamp HC, Keul J. Echocardiographic findings in endurance athletes with hypertrophic non-obstructive cardiomyopathy (HNCM) compared to non-athletes with HNCM and to compared to non-athletes with HNCM and to
physiological hypertrophy (Athlete's Heart). Int $\mathcal{f}$ Sports physiological hypertroph

60 Mitten MJ, Maron BJ. Legal considerations that affect medical liability for competitive athletes with cardiovascular abnormalities and acceptance of Bethesda Conference recommendations. Med Sci Sports Exerc 1994;26:S238-41.

61 Smith DM. Pre-participation physical evaluations. Development of uniform guidelines. Sports Med 1994 18:293-300.

62 Weidenbener EJ, Krauss MD, Waller BF, Talierco CP. Incorporation of screening echocardiography in the preparticipation exam. Clin 7 Sports Med 1995;5:86-9.

63 Franklin B, Kahn JK. Detecting the individual prone to exercise-related sudden cardiac death. Sports Sci Rev exercise-related

64 Chillag S, Bates M, Voltin R, Jones D. Sudden death: myocardial infarction in a runner with normal coronary arteries. Physician Sportsmed 1980;18:89-94.

65 Goodman JM. Exercise and sudden cardiac death. Etiology in apparently healthy individuals. Sports Sci Rev 1995; 4:14-30

66 Torg J. Sudden cardiac death in the athlete. In: Torg J, Shephard RJ, eds. Current therapy in sports medicine. Philadelphia: Mosby/Yearbook, 1995:8-10.

67 Winget JP, Capeless MA, Ades PA. Sudden death in athletes. Sports Med 1994;18:375-83.

68 Spirito P, Chiarella F, Carratino L, Berisso MZ, Bellotti P, Vecchio C. Clinical course and prognosis of hypertrophic cardiomyopathy in an outpatient population. $N$ Engl $\mathcal{F}$ Med 1989;320:749-55.

69 Marian AJ, Kelly D, Mares A, Fitzgibbons J, Caira T, QunTao, et al. A missense mutation in the beta-myosin heavy chain gene is a predictor of premature sudden death in patients with hypertrophic cardiomyopathy. $₹$ Sports Med patients with hypertrophic

70 Sarna S, Sahi T, Koskwenvuo M, Kaprio J. Increased life expectancy of world class male athletes. Med Sci Sport Exerc 1993;25:237-44.

71 Shephard RJ. Physical activity and aging, 2nd ed. London: Croom Helm, 1987.

72 Kavanagh T, Mertens DJ, Matosevic V, Shephard RJ Evans B. Health and aging of Masters athletes. Clin $\mathcal{f}$ Sports Med 1989;1:72-88.

73 Paffenbarger RS, Hyde RT, Wing AL, Lee I-M, Kampert JB. Some interrelations of physical activity, physiologica fitness, health and longevity. In: Bouchard C, Shephard RJ, Stephens T, eds. Physical activity, fitness and health. Champaign, IL. Human Kinetics Publishers, 1994: 119-33.

74 Pekkanen J, Marti B, Nissinen A, Tuomilehto J, Punsar S, Karvonen MJ. Reduction of premature mortality by high physical activity: a 20-year follow-up of middle-aged physical activity: a 20-year follow-ur

75 Shephard RJ. Physical activity and quality-adjusted lifeexpectancy. Quest (in press). 